\title{
Laparoscopic horseshoe kidney isthmusectomy: four case reports
}

\author{
Piotr Jarzemski, Sławomir Listopadzki \\ Department of Urology, Jan Biziel University Hospital, Bydgoszcz, Poland
}

Videosurgery Miniinv (e-pub, ahead of print) DOI: 10.5114/wiitm.2011.35740

\begin{abstract}
Horseshoe kidney is a congenital defect of the urinary tract that occurs in $0.25 \%$ of the general population. The indications for division of the isthmus of horseshoe kidney are controversial, and if done, it is during the concomitant removal of additional defects accompanying horseshoe kidney. The aim of this study was to evaluate the results of isthmusectomy of horseshoe kidney using laparoscopy. This paper presents cases of 4 patients who underwent isthmusectomy, dismembered pyeloplasty, and stone removal using laparoscopy. All patients were operated on by a transperitoneal approach using 4 trocars. In 3 patients, we cut the renal isthmus by means of bipolar scissors and then we closed the renal parenchyma using two continuous hemostatic Vicryl 1-0 stitches. In 1 patient, an endostapler was used for isthmusectomy. The total operative time ranged from $4.5 \mathrm{~h}$ to $5.5 \mathrm{~h}$ including simultaneous dismembered pyeloplasty in 3 patients. Blood loss ranged from $40 \mathrm{ml}$ to $300 \mathrm{ml}$. Use of the endostapler greatly facilitated the procedure. There were no complications either during or after the procedure. In all patients, mobilization and oral nutrition were included on the first or second day. On the third day, all patients were ready to be discharged from the hospital. Long-term follow-up after treatment showed good results in all patients. Laparoscopy is an alternative to open surgery, particularly in the correction of congenital defects of the urinary tract. Although the indications for division of the isthmus of horseshoe kidney are controversial, laparoscopic technique in isthmusectomy is safe for patients, as shown by our results.
\end{abstract}

Key words: laparoscopic techniques, horseshoe kidney, laparoscopy.

\section{Introduction}

Horseshoe kidney is a congenital urinary tract anomaly occurring in $0.25 \%$ of the population, or 1 in 400 of the general population [1]. Horseshoe kidney is a connection of the lower, or rarely, upper renal pole. The renal pelvis faces the front, while the calyxes face the spine. Ureters extending from the front are entangled on the poles connecting the isthmus. Inverted pelvis and ureters entangled on the isthmus cause urine flow hindrance which leads in some cases to an expanded pyelocalyceal system and hydronephrosis. Numerous additional vessels extending from and to the kidney isthmus cross with the ureters, causing ureter obstruction [1]. Urinary outflow obstruction causes urinary retention and formation of calculi in the horseshoe kidney. We recognize ureteropelvic junction obstruction (UPJO) in $24 \%$ of patients with horseshoe kidney [2].

Frequently, the defect does not cause any symptoms and is diagnosed incidentally during routine imaging studies [2]. Some patients complain of abdominal pain but with an indefinite placement. Thirty percent of the respondents affirm a urinary tract infection, and 20-80\% urinary tract stones [1]. We identify horseshoe kidney by employing ultrasound imaging, intravenous pyelography (IVP) or computed tomography (CT). The indications for sur- 
gery are associated with horseshoe kidney abnormalities such as UPJO or nephrolithiasis [3]. Currently, division of the horseshoe kidney isthmus is rarely done, and if it is done, it is during the simultaneous removal of additional defects accompanying horseshoe kidney [3]. The use of laparoscopy for surgery of horseshoe kidney has rarely been described in the literature. The most commonly performed treatment for non-functioning kidney [4-11], or horseshoe kidney cancer [12, 13] was laparoscopic heminephrectomy. In 1996, an operation of cutting vessels which crossed the ureter in a patient with horseshoe kidney was described [14]. In 2002, we presented our first successful laparoscopic isthmusectomy and dismembered pyeloplasty in a patient with horseshoe kidney [15], and in 2005 Kawauchi et al. presented laparoscopic pyeloplasty and isthmusectomy in a 4-year-old boy [16].

In this paper, we present the results of isthmusectomy of horseshoe kidney using laparoscopic tech-

Table I. Patients' characteristics

\begin{tabular}{|lccc|}
\hline $\begin{array}{l}\text { Patient } \\
\text { no. }\end{array}$ & $\begin{array}{c}\text { Age } \\
\text { [years] }\end{array}$ & Recognition - side & $\begin{array}{c}\text { Additional } \\
\text { conditions }\end{array}$ \\
\hline 1 & 15 & Horseshoe kidney - left & UPJO \\
\hline 2 & 14 & Horseshoe kidney - left & UPJO \\
\hline 3 & 34 & Horseshoe kidney - left & Kidney stones \\
\hline 4 & 47 & Horseshoe kidney - right & $\begin{array}{c}\text { UPJO } \\
\text { and kidney } \\
\text { stones }\end{array}$ \\
\hline
\end{tabular}

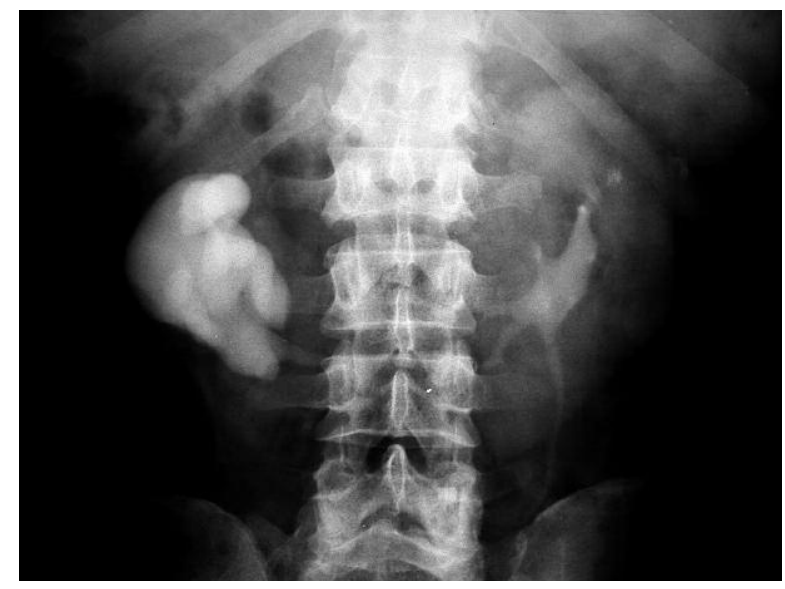

Photo 1. Preoperative IVP (patient no. 4) niques in adult patients hospitalized in the Department of Urology with symptomatic horseshoe kidney associated with UPJO and/or stones.

\section{Case report}

Laparoscopic isthmusectomy of horseshoe kidney included 4 patients aged 14, 15, 34, and 47 years. All patients were admitted to the Department of Urology, The Jan Biziel University Hospital, Bydgoszcz, Poland, for intense abdominal pain. Based on ad hoc ultrasonography (USG), horseshoe kidney was suspected in all patients. Three patients were diagnosed with UPJO, including 1 patient with UPJO coexisting with stones and 1 patient with only kidney stones (Table I).

The diagnosis was confirmed by IVP (Photo 1). The thickness of the isthmus was determined using computed tomography (CT) scans (Photo 2).

All patients qualified for laparoscopic surgical treatment. The patient was placed on his back with raised operated side. The procedure was performed with a transperitoneal approach using four trocars $(2 \mathrm{~mm} \times 5 \mathrm{~mm}$ and $2 \mathrm{~mm} \times 10 \mathrm{~mm}$ ) inserted slightly lower than the laparoscopic nephrectomy or pyeloplasty. A $10 \mathrm{~mm}$ trocar at $30^{\circ}$ optic was located below the umbilicus.

In the first stage, the retroperitoneal cavity procedure was visualized pushing the ascending colon or descending colon to the center, depending on the accompanying horseshoe kidney defect, such as the UPJO and/or stones which occurred in this case. The ureter was visualized, and moving upward along the ureter, the kidney and isthmus were localized. The ureters crossed the isthmus. The treatment was initi-

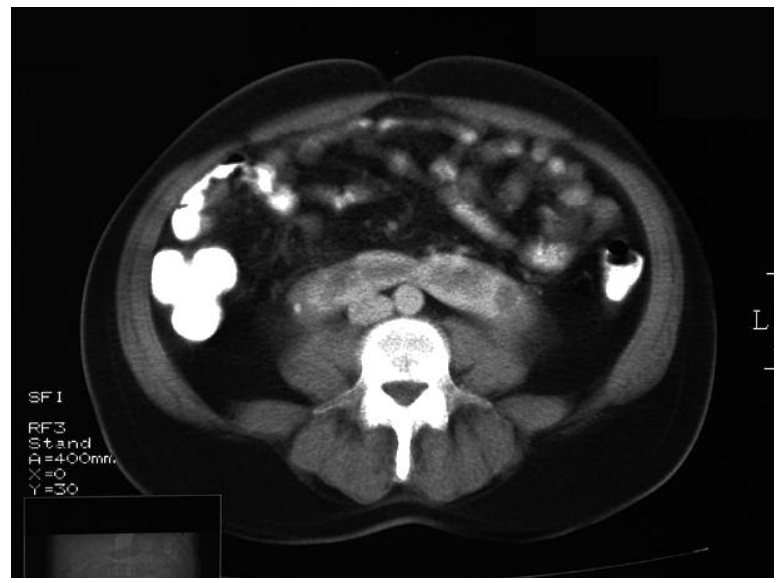

Photo 2. Preoperative CT scan of kidney (patient no. 4) 


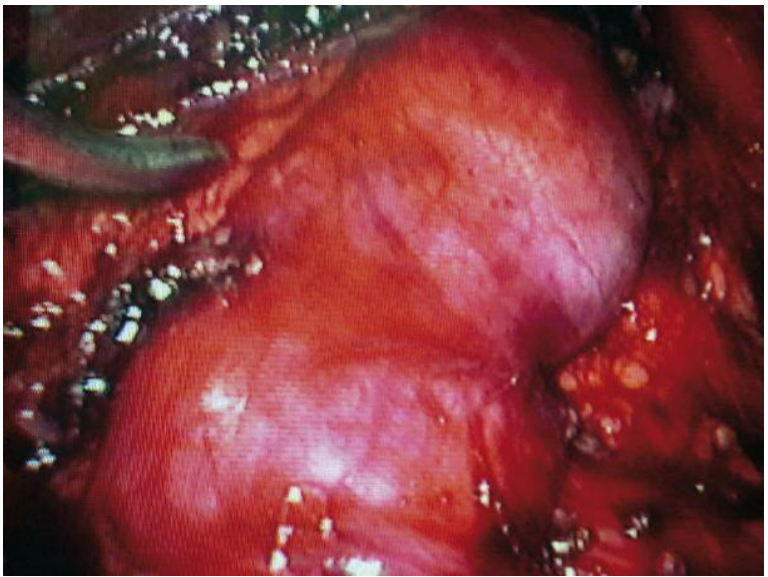

Photo 3. Isthmus of kidney before division

ated with a thorough dissection of the ureter up to the pelvis. Then, isolation of the isthmus connecting the lower poles of the kidneys was performed. Numerous vessels reaching the lower pole and isthmus were located. Preparation of additional vessels was easier than in the classical technique because of the good visibility during laparoscopy. Large blood vessels reaching the lower pole were gently pulled away. Tiny blood vessels leading to the isthmus were initially clipped or coagulated and then cut. None of them were big enough to cause ischemia of the parenchyma. After careful separation of the isthmus from the surrounding tissues, it was raised upward to place the laparoscopic dissector under the isthmus (Photo 3).

Two different techniques for division of the isthmus were used:

1. In 3 patients, after visualization of the isthmus, we put two separate Vicryl 1-0 stitches on the edges of the isthmus (upper and lower on both sides). After this, we pulled the isthmus and cut the renal parenchyma between stitches using bipolar coagulation scissors. Bipolar coagulation did not allow complete hemostasis. We closed the renal parenchyma using two stitches previously established on the edges of the isthmus. The renal parenchyma was stitched by the same continuous hemostatic sutures.

2. In 1 patient (a young boy with a thin isthmus), an endostapler (Tyco) was used to divide the isthmus. The stapler was introduced through a $12-\mathrm{mm}$ trocar, and the isthmus was placed between the arms of the stapler. The stapler placed three rows of parenchymal staples and cut the tissue between the staples (Photos 4 and 5).

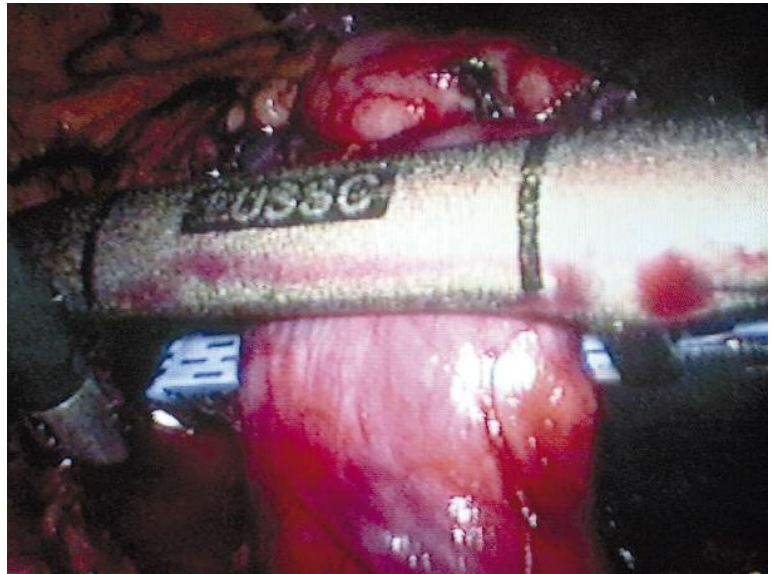

Photo 4. Isthmus of kidney before division using endostapler

The second stage started with dismembered pyeloplasty according to Anderson-Haynes in 3 patients with UPJO, including in one patient in whom pyeloplasty was performed with removal of stones. In the patient without UPJO, stones were removed through a small incision in the renal pelvis.

The total operative time ranged from $4.5 \mathrm{~h}$ to $5.5 \mathrm{~h}$. Blood loss ranged from $40 \mathrm{ml}$ to $300 \mathrm{ml}$. In 1 patient in order to divide the isthmus, an endostapler (Tyco) was used which greatly facilitated the treatment phase and reduced bleeding. For 3 patients after isthmusectomy, we used 1.0 Vicryl suture to close renal parenchymal defects. There were no complications either during or after the procedure. In all patients, motor activity occurred on the first day. Nutrition was enrolled on the first or second day. On the third day, all patients were ready to be discharged from the hospital. Hospitalization time

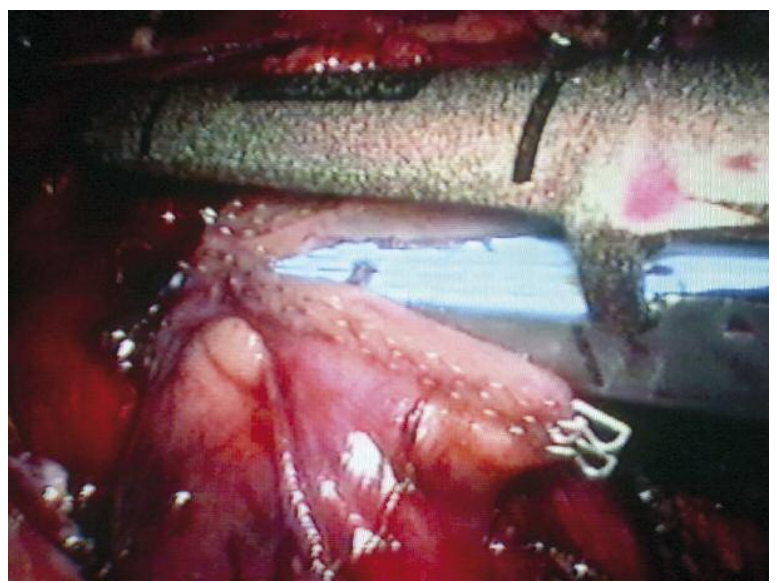

Photo 5. Isthmus of kidney after division using endostapler 
Table II. Operative and postoperative parameters

\begin{tabular}{|c|c|c|c|c|}
\hline \multirow[t]{2}{*}{ Parameter } & \multicolumn{4}{|c|}{ Patient no. } \\
\hline & 1 & 2 & 3 & 4 \\
\hline Operative time [h] & 5 & 5.5 & 4 & 5.5 \\
\hline Tools & Endostapler & Bipolar scissors & Bipolar scissors & Bipolar scissors \\
\hline Blood loss [ml] & 40 & 50 & 300 & 150 \\
\hline Motor activity & First day & First day & First day & First day \\
\hline Nutrition & Second day & First day & Second day & First day \\
\hline Hospitalization time [days] & 8 & 11 & 10 & 8 \\
\hline Double-J catheter [days] & 7 & 9 & No & 21 \\
\hline
\end{tabular}

ranged from 8 to 11 days, and detailed postoperative follow-up and research ensued. In patients after simultaneous dismembered pyeloplasty, a double J stent was placed, which was removed on the seventh, ninth and twenty-first days (Table II). As in other cases of laparoscopic surgery, satisfactory cosmetic results were observed after this particular surgery. Control examination 6 months following the opera-

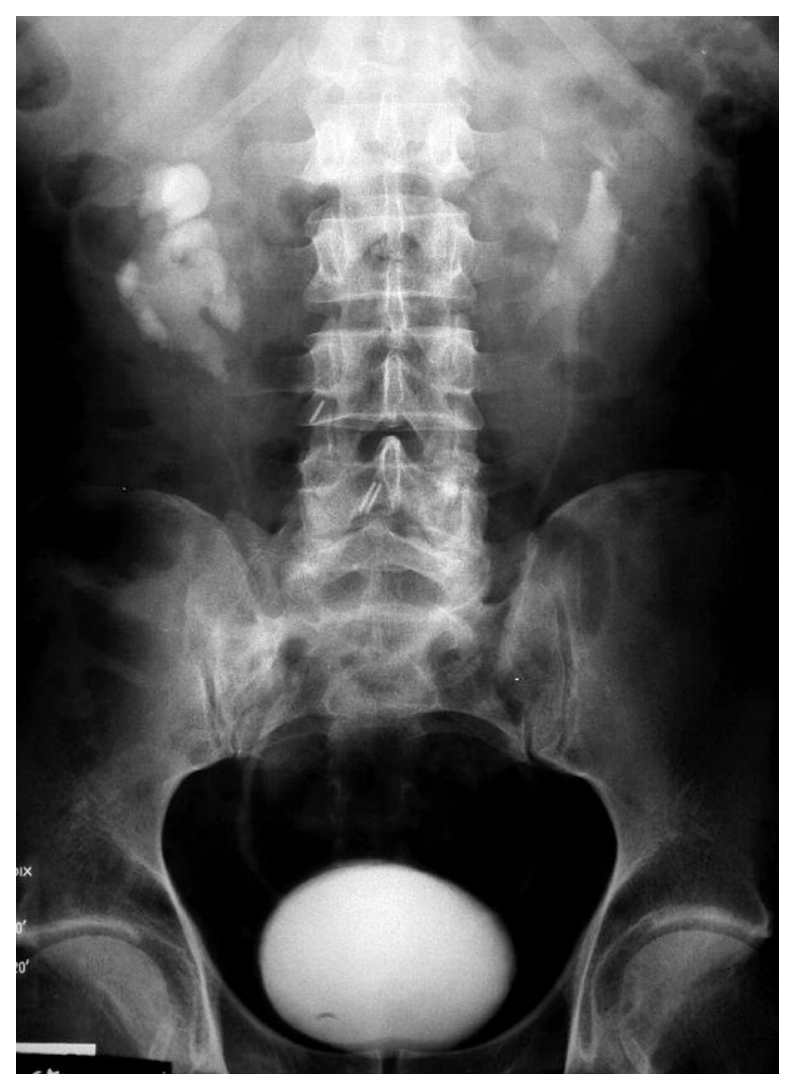

Photo 6. Postoperative IVP (patient no. 4) tion showed good effects of the operation and subsided symptoms in all patients (Photo 6).

\section{Discussion}

Horseshoe kidney is a congenital defect that occurs in 1 in 400 individuals. It is twice as often diagnosed in men as in women. It is often accompanied by other anomalies of the pyelocalyceal system [17, 18]. Cascio et al. recognized defects associated with horseshoe kidney in 26 (52\%) of the 50 comprehensively examined children with horseshoe kidney. Frequently, it was vesicoureteral reflux in 13 children (32\%) and UPJ obstruction in 12 (24\%). Of the 26 children who were diagnosed with defects associated with horseshoe kidney, 15 (58\%) required surgical intervention, including 8 with UPJ obstruction [2].

Difficult urine outflow is due to the course of the ureter, which comes out anteriorly of the pelvis and crosses the isthmus of the kidney. In addition, numerous vessels extending into the isthmus and lower pole may cross the ureter [1]. The consequence due to obstruction of the urine outflow may be destruction of the renal parenchyma. In addition, it also favors the formation of stones [1].

Patients with horseshoe kidney may not display any symptoms. If there are any symptoms, the most frequently reported ones include abdominal pain, vomiting and nausea. Cascio, in his work, observed various symptoms in 42 of the 50 examined children. The majority of them $(24 ; 57 \%)$ had additional defects such as UPJ obstruction or vesicoureteral reflux [2].

As observed in our case studies, all patients reported recurrent, severe pain, requiring the use of analgesics. Therefore, patients were hospitalized sev- 
eral times in emergency departments. Horseshoe kidney UPJ obstruction and/or stones, which were observed during diagnostic imaging, were direct indications for medical treatment. In our center, we do not perform surgery on patients with asymptomatic horseshoe kidney conditions. For UPJO, laparoscopic dismembered pyeloplasty is a standard technique in our department. Previous experience has allowed us to use the laparoscopic technique to repair UPJO and remove stones in horseshoe kidney. During the last 10 years, we decided to perform such operations only in 4 patients. In all 4 patients, the laparoscopic technique achieved good final results.

The aim of the surgery was laparoscopic dismembered pyeloplasty and stone removal. During the surgical procedure, the isthmus, connecting the lower poles of the kidneys, was divided. The decision for isthmusectomy was determined by the position of the ureter and a high probability of living with compression and obstructed upper urinary tract.

No need to divide the isthmus in horseshoe kidney, described in 1972 by Kölln and Boatman, is the currently accepted principle of procedure [17]. However, isthmusectomy may be a useful adjunctive measure to allow repositioning of the kidney and maintenance of an unobstructed upper urinary tract [3]. That was true in our cases. Dissection of the isthmus and the decision for division proved to be easier during laparoscopic surgery than during open surgery. In our opinion, if we have doubts about the success of the operation, the decision to perform isthmusectomy may be necessary. Using laparoscopic technique isthmusectomy is not risky but safe for the patients, as shown by our results. We had such doubts in all 4 cases and concluded that the simultaneous division of the isthmus of horseshoe kidney during laparoscopic surgery, where we have an excellent insight into the operative field, will be less stressful and risky to the patient than the exposure of the failure of the dismembered pyeloplasty. A similar decision was made by some other authors, likely in fear of failure of operation $[16,19,20]$. Horseshoe kidney and UPJO are rare cases, and it is therefore difficult to collect an appropriate group to compare the results in a single center. However, our results demonstrated the validity and integrity of the decision.

Currently we do not operate or divide the isthmus in cases of an asymptomatic horseshoe kidney. Isthmusectomy can be justified only as a simultaneous action in the event of a decision in surgery because of other defects associated with horseshoe kidney or kidney stones, and it is performed only when division of the isthmus will be necessary to maintain proper drainage of urine after treatment [3]. Laparoscopic technique is much less stressful for the patient than the classic operation techniques. In our opinion, in a select group of patients, we can divide the isthmus laparoscopically if repositioning the kidney after the intersection is a necessary solution to guarantee the free outflow of urine. Repositioning of the kidney can significantly reduce the risk of re-compression of the ureter, and the failure of UPJ pyeloplasty.

The anterior position of the renal pelvis facilitates UPJ pyeloplasty. In one of the analyzed cases, the difficulties stemmed from a very extensive network of small blood vessels which were entangled on and oppressing the ureter. Only cutting and repositioning the kidney freed the course of the ureter.

The technique of hemostasis is a major problem during a laparoscopic procedure [21-23]. In our cases also the biggest problem during separation of the isthmus was the hemostasis. Use of scissors with bipolar coagulation was not enough. Prior suturing of the upper and lower edges of the isthmus proved to be very useful; sutures were used to support the kidney, and after division of the isthmus - with the same sutures - we put a continuous suture on the parenchyma.

In 1 patient with a relatively narrow fibrous isthmus to its intersection, an endostapler was used, which greatly facilitated the stage of division of the isthmus without the need to suture the parenchyma. Earlier studies have reported cases of non-functioning horseshoe kidney heminephrectomy with use of bipolar coagulation [24], microwave coagulation [25], harmonic scalpel [5], Ligasure ${ }^{\circledR}$ [16], and an endostapler $[24,26]$ for the division of the isthmus. Coagulation seems to be insufficient, and in our opinion, stitches on the parenchyma are necessary. Atif Khan, in his paper, clipped the isthmus with a $15-\mathrm{mm} \mathrm{Hem}$ o-lok and divided it with a harmonic scalpel. A PDS Endoloop was also tied around the isthmus [8]. The ideal solution to completely avoid bleeding seems to be the stapler, but its use is possible only in the case of a narrow isthmus.

Total operative time ranged from $4 \mathrm{~h}$ to $5.5 \mathrm{~h}$, including UPJ pyeloplasty and removal of stones. Division of the isthmus of the kidney lasted about $1 \mathrm{~h}$ to $1.5 \mathrm{~h}$. The operation was significantly longer than conventional treatments but the recovery time was 
significantly shorter and the cosmetic result much better. After surgery, the patients did not require use of any analgesics. Patients were discharged home later, but longer hospitalization time resulted from a desire for careful observation of the first patients after such operations and for a university research program. Subsequent patients will be able to leave the hospital much earlier. In all patients the postoperative period was uncomplicated.

In conclusion, laparoscopic technique is an alternative to open surgery, particularly in the correction of congenital defects of the urinary tract. Although the indications for division of the isthmus of horseshoe kidney are controversial, in the case of the need for this type of surgery, the laparoscopic method may become a technique of choice and can successfully replace open operations. In our opinion, if we have doubts about the success of the operation, the decision for isthmusectomy may be necessary. Using laparoscopic isthmusectomy is not risky but safe for the patients, as shown by our results.

\section{References}

1. Bauer S. Anomalies of the upper urinary tract. Horseshoe kidney.

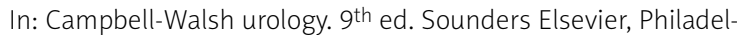
phia, 2007; 3287-91.

2. Cascio S, Sweeney B, Granata C, et al. Vesicoureteral reflux and ureteropelvic junction obstruction in children with horseshoe kidney: treatment and outcome. J Urol 2002; 167: 2566-8.

3. Novick AC. Open surgery of the kidney. Isthmusectomy for horseshoe kidney. In: Campbell-Walsh urology. $9^{\text {th }}$ ed. Sounders Elsevier, Philadelphia 2007; 1755-6.

4. Donovan JF, Cooper CS, Lund GO, Winfield HN. Laparoscopic nephrectomy of a horseshoe kidney. J Endourol 1997; 11: 181-4.

5. Lapointe SP, Houle AM, Barrieras D. Retroperitoneoscopic left nephrectomy in a horseshoe kidney with the use of the harmonic scalpel. Can J Urol 2002; 9: 1651-2.

6. Yohannes P, Dinlenc C, Liatsikos E, et al. Laparoscopic heminephrectomy for benign disease of the horseshoe kidney. JSLS 2002; 6: 381-4

7. Hemal AK, Gupta NP, Wadhwa SN, et al. Retroperitoneoscopic nephrectomy and nephroureterectomy for benign nonfunctioning kidneys: a single-center experience. Urology 2001; 57: 644-9.

8. Khan A, Myatt A, Palit V, Shekhar-Biyani C. Laparoscopic heminephrectomy of a horseshoe kidney. JSLS 2011; 15: 415-20.

9. Yao D, Poppas DP. A clinical series of laparoscopic nephrectomy, nephroureterectomy and heminephroureterectomy in the pediatric population. J Urol 2000; 163: 1531-5.

10. Donovan JF, Cooper CS, Lund GO, et al. Laparoscopic nephrectomy of a horseshoe kidney. J Endourol 1997; 11: 181-4.

11. Riedl CR. Huebner WA. Schramek I, et al. Laparoscopic heminephrectomy in a horseshoe kidney. Br J Urol 1995; 76: 140-1.
12. Kitamura H, Tanaka T, Miyamoto D, et al. Retroperitoneoscopic nephrectomy of a horseshoe kidney with renal-cell carcinoma. J Endourol 2003; 17: 907-8.

13. Del Biondo D, Celia A, Zeccolini G, Breda G. Laparascopic heminephrectomy in horseshoe kidney: a case report. Arch Ital Urol Androl 2010; 82: 175-7.

14. Keeley FX Jr, Bagley DH, Kulp-Hugues D, et al. Laparoscopic division of crossing vessels at the ureteropelvic junction. J Endourol 1996; 10: 163-8.

15. Listopadzki S, Jarzemski P. Laparoscopic isthmotomy and dismembered pyeloplasty by the patient with horseshoe kidney. Eur Urol 2002; 1: 57.

16. Kawauchi A, Fujito A, Yoneda K, et al. Laparoscopic pyelopyeloplasty and isthmectomy for hydronephrosis of horseshoe kidney: a pediatric case. J Endourol 2005; 19: 984-6.

17. Kölln CP, Boatman DL, Schmidt JD, et al. Horseshoe kidney: a review of 105 patients. J Urol 1972; 107: 203-4.

18. Boatman DL, Kölln CP, Flocks RH. Congenital anomalies associated with horseshoe kidney. J Urol 1972; 107: 205-7.

19. Nadler RB, Thaxton CS, Kim SC. Hand-assisted laparoscopic pyeloplasty and isthmectomy in a patient with a horseshoe kidney. J Endourol 2003; 17: 909-10.

20. Yamaguchi K, Tanaka K, Nakano Y, et al. Laparoscopic pyeloplasty for ureteropelvic junction obstruction. Nihon Hinyokika Gakkai Zasshi 2006; 97: 737-42.

21. Petrasz P, Stojewski M, Sikorski A. Impact of "non-clamping technique" on intra- and postoperative course after laparoscopic partial nephrectomy. Videosurgery Miniinv 2012; 7: 275-9.

22. Chlosta P, Drewa T, Siekiera J, et. al. Lymph node dissection during laparoscopic (LRC) and open (ORC) radical cystectomy due to muscle invasive bladder urothelial cancer (pT2-3, TCC). Videosurgery Miniinv 2011; 6: 127-31.

23. Bryks-Laszkowska A, Gołębiewski A, Czauderna P. Laparoscopic single port surgery nephrectomy in a child - initial experience. Videosurgery Miniinv 2012; 7: 304-6.

24. Nouri-Mahdavi K, Izadpanahi MH. Laparoscopic heminephrectomy in horseshoe kidney using bipolar energy: report of three cases. J Endourol 2008; 22: 667-70.

25. Hayakawa K, Baba S, Aoyagi T, et al. Laparoscopic heminephrectomy of a horseshoey kidney using microwave coagulator. J Urol 1999; 161: 1559.

26. Tan YH, Young MD, Preminger GM, Albala DM. Hand-assisted laparoscopic heminephrectomy in horseshoe kidney. J Endourol 2004; 18: 562-4

Received: 28.03.2013, accepted: 16.05.2013. 